\title{
Proses Bisnis Layanan Medical Checkup (MCU) Menggunakan Business Process Model and Notation (BPMN)
}

\author{
Akhmad Bakhrun ${ }^{1}$ dan Jonner Hutahaean ${ }^{2}$ \\ 1,2Jurusan Teknik Komputer dan Informatika, Politeknik Negeri Bandung \\ abakhrun@polban.ac.id ${ }^{1}$ dan jonnerh@jtk.polban.ac.id ${ }^{2}$
}

\begin{abstract}
Diajukan 14 November 2020 Diperbaiki 9 Februari 2021 Diterima 12 Februari 2021
ABSTRAK
\end{abstract}

Latar Belakang: Layanan medical check up (MCU) dibutuhkan untuk berbagai keperluan, di antaranya untuk persyaratan pengangkatan Pegawai Negeri Sipil (PNS). Pasien yang menjalani MCU perlu mengetahui proses yang harus diikuti, lama proses, dan jadwal penerimaan hasil agar pasien dapat mempersiapkan diri dengan baik. Di sisi lain, manajemen rumah sakit juga perlu mengevaluasi layanan MCU agar selalu unggul, kompetitif, dan berkelanjutan.

Tujuan: Membangun model proses bisnis layanan MCU dalam persyaratan pengangkatan PNS.

Metode: Observasi dan eksplorasi untuk menganalisis proses bisnis layanan MCU serta mempelajari dokumen hasil MCU seperti hasil pemeriksaan laboratorium dan thorax serta surat hasil MCU yang telah disahkan oleh ketua tim penguji kesehatan rumah sakit. Pemodelan proses bisnis dibuat menggunakan BPMN dengan tool Bizagi.

Hasil: Model proses bisnis untuk panduan pasien dan peningkatan layanan MCU dapat diimplementasikan menjadi Standard Operating Procedure (SOP) layanan MCU di rumah sakit. Selain itu, model ini merupakan requirement awal yang sangat penting untuk membangun perangkat lunak pencatatan data MCU yang terintegrasi.

Kesimpulan: Adanya model proses BPMN dapat memudahkan pasien untuk mengetahui tahapan proses MCU yang sedang mereka jalani dan perkiraan waktu selesainya. Manajemen rumah sakit juga dapat menjadikan model ini untuk mengevaluasi dan meningkatkan layanan MCU.

Kata Kunci: MCU; PNS; BPMN; SOP; perangkat lunak

\section{ABSTRACT}

Background: Medical checkup (MCU) services are needed for various purposes, including Civil Servants promotion. Patients who will take an MCU need to know the process, how long it will take, and when the results can be known so that they can prepare themselves well. Besides, hospital management also needs to evaluate MCU services to keep their superiority, competitiveness, and sustainability.

Objective: Create an MCU service business process model for civil servant appointment requirements.

Method: Observation and exploration to analyze MCU service business processes and study the documents of MCU results such as laboratory and thorax examinations as well as the results approved by the hospital's health examiner team. The business process modeling was made using BPMN with the Bizagi tool.

Results: Business process model for patient guidance and improvement of MCU services could be implemented as a Standard Operating Procedure (SOP) for MCU services in hospitals. In addition, this model was a very important initial requirement to develop integrated MCU record software.

Conclusion: By using this BPMN on MCU process, patients will be easier to monitor the staging process. Hospital management can also use this model to evaluate and improve MCU services.

Keywords: $M C U$; civil servants; BPMN; SOP; software 
PENDAHULUAN

Kebutuhan untuk memeriksakan kesehatan (medical check up/MCU) secara berkala tampaknya masih belum menjadi prioritas bagi sebagian orang walaupun MCU diharapkan dapat menilai kesehatan seseorang berdasarkan wawancara medis, pemeriksaan fisik, dan pemeriksaan penunjang tertentu yang diperlukan (Humas RSHS, 2019a).

MCU sebaiknya dilakukan secara berkala untuk mengetahui kondisi kesehatan terkini sehingga dapat mempersiapkan diri sejak awal apabila teridentifikasi adanya gangguan atau kelainan kesehatan. MCU juga digunakan untuk mengetahui potensi adanya risiko penyakit yang akan muncul sehingga mendorong seseorang untuk beralih menuju pola hidup yang sehat (Humas RSHS, 2019a). Selain itu, MCU dibutuhkan untuk memenuhi berbagai persyaratan khususnya untuk pengangkatan PNS.

Hingga saat ini, lowongan formasi PNS selalu dinantikan oleh para pencari kerja (Haryanto, 2019; Idhom, 2019). Salah satu persyaratan untuk pengangkatan PNS adalah harus lulus MCU dari rumah sakit yang menjadi rujukan pemerintah. Faktanya, proses MCU secara umum adalah sama, yaitu pendaftaran, pemeriksaan fisik, pemeriksaan laboratorium, hingga analisis kesimpulan. Namun, spesifikasi layanan MCU bisa berbeda tergantung dari paket MCU yang dipilih sesuai peruntukannya.

Rumah Sakit Hasan Sadikin (RSHS) menawarkan lima jenis paket MCU, yaitu: (1) Paket Ekonomi untuk pelajar atau pekerja; (2) Paket Dasar untuk pengangkatan PNS 100\%; (3) Paket Bisnis A untuk bekerja atau kuliah di luar negeri; (4) Paket Lengkap; dan (5) Paket Eksekutif dengan perjanjian khusus (Humas RSHS, 2019b). Tiap paket tentu saja memiliki harga yang berbeda dan sewaktu-waktu bisa saja berubah.

Berdasarkan sisi bisnis, layanan MCU merupakan peluang bisnis yang sangat potensial dan pasti karena rekrutmen dan regenerasi PNS akan selalu terjadi. Jika dalam satu tahun terdapat 254.173 PNS menjalani MCU dengan biaya 450.000 per pasien, uang yang terserap untuk layanan MCU dapat mencapai Rp14.377.850.000 per tahun. Nominal tersebut pun belum termasuk PNS yang harus mengulang MCU atau pasien selain PNS yang membutuhkan layanan MCU dengan paket yang berbeda.

Melihat peluang bisnis yang besar dan pasti ini, rumah sakit harus terus mengevaluasi proses bisnis layanan MCU agar penggunaan sumber daya untuk layanan tersebut menjadi lebih efisien (Cebeci \& Kol, 2013). Proses bisnis adalah urutan aktivitas atau langkah-langkah dalam konteks bisnis untuk menghasilkan barang atau jasa sesuai dengan kebutuhan pengguna (Buttigieg et al., 2016). Rumah sakit harus mengelola proses bisnis yang dimilikinya agar dapat memberikan layanan medis yang berkualitas (Ruiz et al., 2012). Rumah sakit juga harus mampu memahami dan bereaksi secara tepat terhadap peristiwa bisnis sebagai kunci untuk mempertahankan daya saing yang berkelanjutan (Keramati et al., 2011).

Namun demikian, proses layanan MCU memiliki beberapa tantangan seperti duplikasi pekerjaan tenaga medis, kompleksitas pekerjaan, kurangnya komunikasi antara aktor yang terlibat, waktu tunggu yang lama, atau tempat tunggu pasien yang tidak nyaman (Fernández et al., 2020). Tantangan semacam ini dapat mengakibatkan proses layanan MCU tidak efisien sehingga meningkatkan biaya yang harus ditanggung oleh rumah sakit.

Strategi mengelola proses bisnis layanan MCU dapat diterapkan untuk optimalisasi proses administrasi dan proses medis serta mengotomatiskan sebagian pekerjaan tenaga medis. Proses administrasi dilakukan oleh staf administrasi dan melibatkan pelaksanaan 
tugas operasional rumah sakit seperti pendaftaran pasien, pengaturan jadwal petugas medis, pembayaran layanan pemeriksaan, pencetakan hasil pemeriksaan, dan monitoring peralatan laboratorium habis pakai (Fernández et al., 2020).

Proses medis dilakukan oleh tenaga medis dan terkait langsung dengan kesehatan pasien seperti pemeriksaan fisik, pengambilan spesimen darah, pengambilan spesimen urine, pemeriksaan thorax, dan penilaian tes oleh spesialis (Fernández et al., 2020). Manajemen proses merupakan kunci utama dalam keberhasilan organisasi (Gomes et al., 2018). Manajemen proses bisnis dilakukan untuk mendesain ulang proses layanan MCU, meningkatkan optimasi dengan menyederhanakan alur kerja dan menghilangkan tugas-tugas yang tidak menambah nilai pada proses, standardisasi proses, meningkatkan kualitas proses layanan kesehatan, mengurangi biaya dan waktu, serta meningkatkan kinerja manajemen (Buttigieg et al., 2016; Fernández et al., 2020; Juan D et al., 2016; Koncevičs et al., 2017; van der Aalst, 2013).

Manajemen rumah sakit perlu memperbaiki dan meningkatkan proses bisnisnya untuk menjaga keunggulan di tengah lingkungan ketidakpastian yang terus menerus (Juan D et al., 2016). Pemodelan proses diperlukan untuk menyajikan informasi menjadi lebih jelas dan terstruktur serta pemahaman dan komunikasi yang lebih baik dari proses organisasi (Lodhi et al., 2011; Recker et al., 2009).

Pemodelan proses bisnis juga diperlukan untuk mengidentifikasi area aktivitas mana yang bisa ditingkatkan (Cebeci \& Kol, 2013). Pemodelan proses dapat dijelaskan secara grafis melalui notasi proses yang disebut BPMN (Kufner \& Marik, 2019).

BPMN adalah tool standar untuk representasi dan analisis proses bisnis
(Fernández et al., 2020; Ramos-Merino et al., 2019). Alat ini merupakan sarana komunikasi antara departemen, peran pemangku kepentingan, sistem, pelanggan, pemasok, pelaksana proses bisnis yang berbeda dan menjembatani kesenjangan komunikasi antara perancang dan pengembang perangkat lunak (Dechsupa et al., 2019; Kazemzadeh et al., 2015; Zafar et al., 2019).

BPMN didukung oleh lebih dari 20 tool yang telah distandardisasi oleh Object Management Group (OMG) dan telah dikenal serta diadopsi secara luas dalam proses pengembangan perangkat lunak (Dechsupa et al., 2019; Flowers \& Edeki, 2013; Wynn et al., 2009; Yamasathien \& Vatanawood, 2014; Zafar et al., 2019).

$$
\text { BPMN berguna untuk }
$$
mendeskripsikan pemodelan proses bisnis yang kompleks secara detail menjadi terstandardisasi dengan notasi yang mudah dipahami oleh semua analis dan pengembang bisnis (Fernández et al., 2020; Nuzulita et al., 2020; Zafar et al., 2019). Pemodelan proses bisnis dibahas dari perspektif pengembangan sistem informasi atau perangkat lunak (Keramati et al., 2011; Lodhi et al., 2011; van der Aalst, 2013). BPMN tidak tergantung pada metodologi yang diterapkan untuk pemodelan proses. Pada penelitian ini, BPMN digunakan untuk memodelkan proses bisnis layanan MCU paket dasar (untuk pengangkatan PNS 100\%) dengan studi kasus di RSHS Bandung, Jawa Barat.

\section{METODE}

Penelitian ini dimulai dari kajian literatur untuk mempelajari aturan-aturan yang berkaitan dengan layanan MCU. Penulis membagi aturan menjadi dua, yaitu aturan internal dan eksternal. Aturan internal berkaitan dengan proses layanan MCU yang ditetapkan oleh rumah sakit, sedangkan aturan eksternal berkaitan dengan pengangkatan PNS yang mensyaratkan harus lulus MCU dari rumah sakit yang ditunjuk oleh 
pemerintah.

Kedua aturan tersebut menjadi satu kesatuan yang tak terpisahkan dalam hal pengangkatan abdi negara. Meskipun pada prinsipnya, rumah sakit dapat melayani pasien MCU baik atas permintaan sendiri maupun atas permintaan institusi lain dengan atau tanpa surat pengantar, dalam hal pengangkatan PNS, pasien yang akan menjalani MCU harus melampirkan surat pengantar dari instansinya masingmasing. Dengan kata lain, pasien tidak bisa melakukan MCU atas inisiatif sendiri.

Setelah kajian literatur, penulis melakukan observasi terhadap pelaksanaan MCU. Observasi adalah salah satu metode penelitian paling penting dalam ilmu sosial dan sekaligus salah satu yang paling beragam (Ciesielska \& Jemielniak, 2018). Observasi dilakukan pada setiap layanan MCU dari pendaftaran sampai analisis kesimpulan hasil MCU. Selain itu, penulis sendiri menjadi pasien MCU sehingga dapat melakukan observasi terhadap seluruh alur MCU secara langsung.

Tahap berikutnya, yaitu melakukan identifikasi terhadap seluruh proses bisnis MCU untuk menganalisis proses layanan MCU yang sedang berjalan (AS-IS), misalnya aktivitas apa yang dilakukan, siapa yang bertanggung jawab, dan peran apa yang terlibat di dalamnya.

Berdasarkan observasi, setidaknya ada sebelas proses bisnis layanan MCU yang teridentifikasi, yaitu: pendaftaran; (2) pembayaran; pemeriksaan fisik; (4) pemeriksaan buta warna; (5) pemeriksaan spesimen darah; (6) pemeriksaan spesimen urin; (7) pemeriksaan Thorax; (8) pengambilan hasil pemeriksaan Thorax; (9) analisis kesimpulan; (10) pengesahan hasil MCU; dan (11) pengambilan hasil MCU. Setelah mengidentifikasi proses bisnis, langkah berikutnya adalah melakukan analisis terhadap semua proses bisnis, lalu membuat model untuk setiap proses bisnis yang telah dianalisis (TO-BE). Pemodelan proses bisnis dijelaskan secara grafis menggunakan BPMN dengan tool Bizagi versi 3.3.x.

\section{HASIL DAN PEMBAHASAN}

Bagian ini berisi pembahasan terhadap sebelas proses bisnis layanan MCU yang telah diidentifikasi. Digunakan pendekatan induktif untuk membahas setiap proses bisnis yang ada. Pembahasan diawali dengan menjelaskan proses bisnis secara rinci, kemudian proses bisnis tersebut disimpulkan secara visual dalam bentuk diagram BPMN agar menjadi lebih mudah dipahami.

\section{Proses Bisnis Pendaftaran}

Pendaftaran adalah tahap awal yang harus dilakukan oleh pasien MCU. Resepsionis MCU akan menanyakan tujuan pasien melakukan MCU, lalu memberitahukan paket layanan MCU yang sesuai dengan kebutuhannya. Bagi pasien yang melakukan MCU untuk syarat pengangkatan PNS, harus menyertakan surat Permohonan Pemeriksaan Kesehatan (PPK) dari instansi asalnya. Nomor surat PPK tersebut akan dicantumkan oleh pihak rumah sakit pada saat mengeluarkan surat hasil MCU.

Resepsionis MCU akan meminta pasien untuk mengisi formulir layanan MCU. Setelah mengisi formulir MCU, pasien mengembalikan formulir tersebut ke resepsionis MCU dan akan diperiksa kelengkapan datanya. Jika terdapat data yang belum lengkap, resepsionis MCU akan meminta pasien untuk melengkapi kembali data tersebut. Jika data sudah lengkap, resepsionis MCU menginput data MCU ke sistem.

Setelah data tercatat di sistem, resepsionis MCU mencetak invoice dan memberikan invoice tersebut kepada pasien untuk segera melakukan pembayaran layanan MCU. Proses ini secara normal membutuhkan waktu lima 
Proses Bisnis Layanan Medical Checkup (MCU)...

menit. Gambar 1 memperlihatkan proses bisnis pendaftaran MCU.

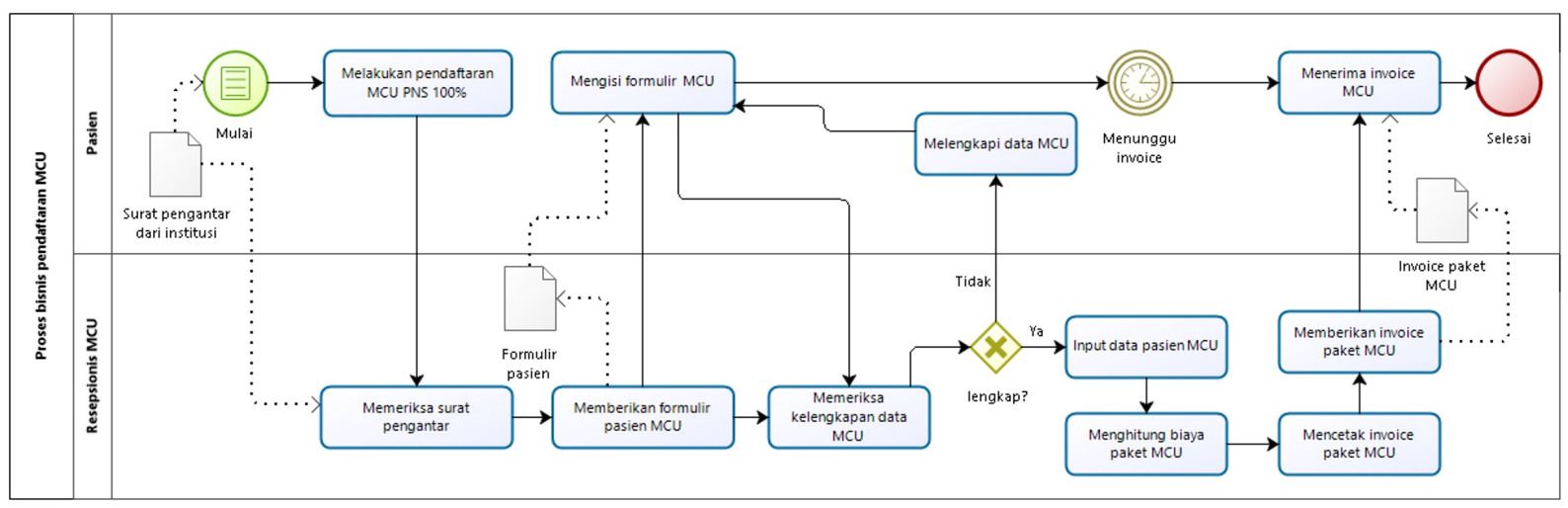

Gambar 1. Proses Bisnis Pendaftaran

Proses Bisnis Pembayaran

Pada tahap ini, pasien terlebih dahulu menyerahkan invoice yang diperoleh pada tahap pendaftaran ke bagian pembayaran. Bagian pembayaran akan melakukan verifikasi data invoice. Setelah invoice terverifikasi, pasien melakukan pembayaran dan menunggu sampai mendapatkan kuitansi pembayaran layanan MCU. Bagian pembayaran memproses pembayaran pasien dan mencetak kuitansi pembayaran untuk semua jenis layanan sesuai paket MCU yang dipilih oleh pasien.

Kuitansi pembayaran dicetak rangkap tiga, yaitu untuk bagian pembayaran, tiap layanan MCU, dan pasien. Bagian pembayaran akan memberikan uang kembalian kepada pasien jika pasien membayar lebih dari harga paket layanan MCU. Proses ini secara normal membutuhkan waktu lima menit. Gambar 2 memperlihatkan proses bisnis pembayaran MCU.

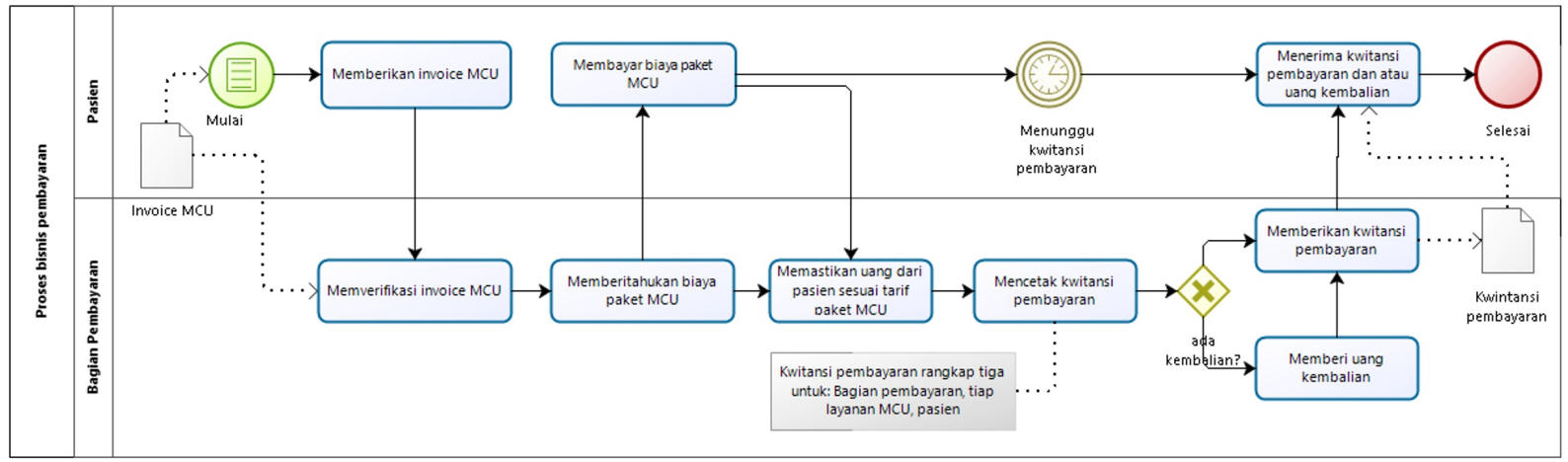

Proses Bisnis Pemeriksaan Fisik

Gambar 2. Proses Bisnis Pembayaran

Setelah melakukan pembayaran, pasien menjalani pemeriksaan fisik dengan terlebih dahulu menyerahkan kuitansi pembayaran yang terkait layanan tersebut. Tenaga medis meminta pasien untuk menimbang berat badan dan tinggi badan, kemudian melakukan pemeriksaan terhadap fisik pasien seperti tensi darah, detak jantung, gigi, menanyakan riwayat penyakit, dan menanyakan perokok aktif/ pasif.
Data hasil pemeriksaan dicatat oleh tenaga medis, lalu pasien diarahkan untuk melakukan pemeriksaan buta warna. Proses ini secara normal membutuhkan waktu 3-5 menit. Gambar 3 memperlihatkan proses bisnis pemeriksaan fisik. 
Proses Bisnis Layanan Medical Checkup (MCU)...

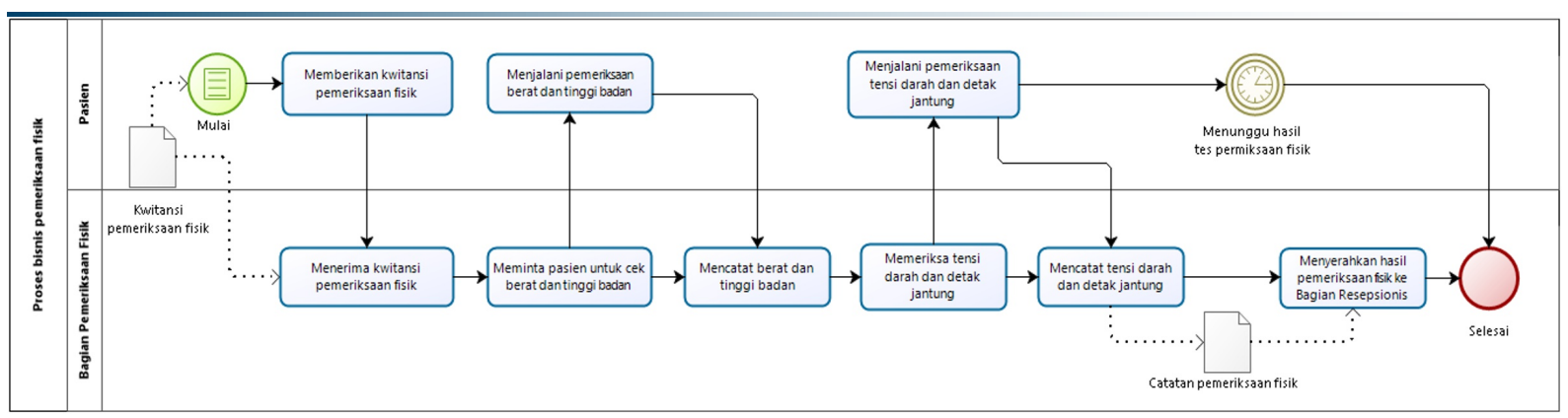

Proses Bisnis Pemeriksaan Buta Warna

Setelah menjalani pemeriksaan fisik, pasien menjalani layanan pemeriksaan buta warna dengan terlebih dahulu menyerahkan kuitansi pembayaran yang terkait layanan tersebut. Tenaga medis meminta pasien untuk membaca angkaangka yang ada di buku tes buta warna, mulai dari angka yang mudah dibaca sampai angka yang paling blur karena dikelilingi oleh pola warna yang mengaburkan bentuk dari angka tersebut.

Selain itu, tenaga medis meminta pasien untuk membaca huruf pada jarak tertentu, mulai dari huruf yang berukuran besar hingga huruf yang berukuran kecil. Pasien membaca huruf menggunakan mata sebelah kanan dan menutup mata sebelah kiri secara bergantian. Tenaga medis mencatat hasil pemeriksaan buta warna pasien, lalu mengarahkan pasien ke bagian laboratorium pemeriksaan spesimen darah. Proses ini secara normal membutuhkan waktu 3-5 menit. Gambar 4 memperlihatkan proses bisnis pemeriksaan buta warna.

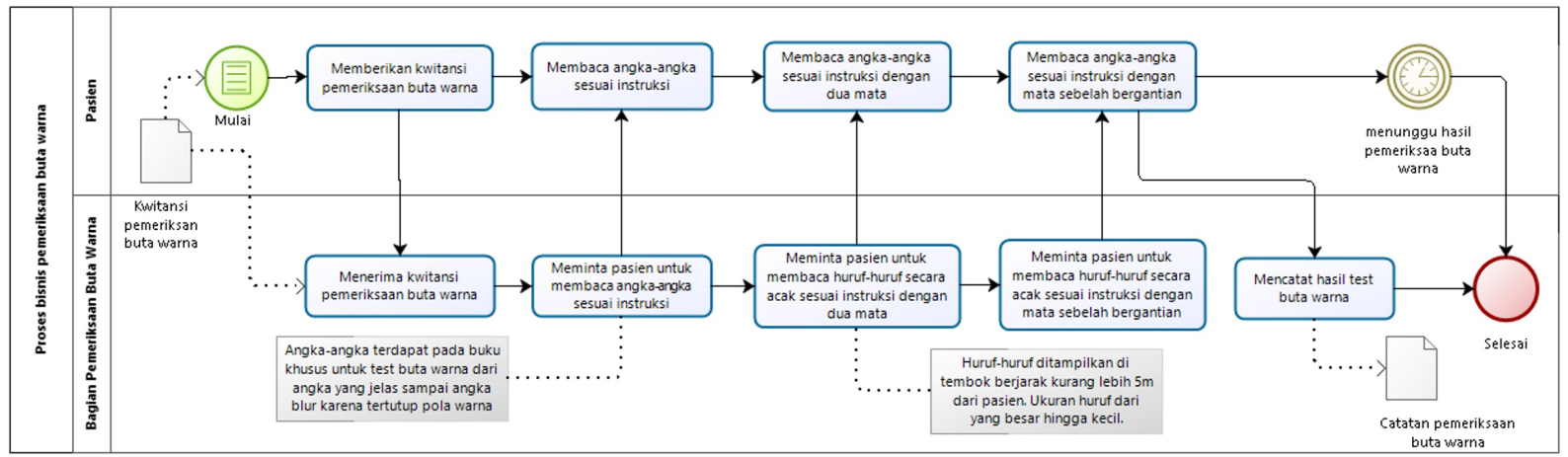

Gambar 4. Proses Bisnis Pemeriksaan Buta Warna

\section{Proses Bisnis Pemeriksaan Spesimen Darah}

Setelah menjalani pemeriksaan buta warna, pasien menjalani pemeriksaan spesimen darah dengan terlebih dahulu menyerahkan kuitansi pembayaran yang terkait layanan tersebut. Bagian laboratorium mengambil spesimen darah pasien untuk melakukan pemeriksaan Hematologi dan Kimia. Pemeriksaan hematologi 14 parameter, yaitu: (1) Hemoglobin; (2) Hematokrit; (3) Eritrosit; (4) Leukosit; (5) Trombosit; (6) MCV; (7) $\mathrm{MCH}$; (8) MCHC; (9) Basofil; (10) Eosinofil; (11) Neutrofil Batang; (12) Neutrofil Segmen; (13) Limfosit; dan (14) Monosit, sedangkan pemeriksaan kimia sebanyak empat parameter, yaitu: (1)
Glukosa puasa; (2) SGOT (AST); (3) SGPT (ALT); dan (4) Kreatinin.

Bagian laboratorium menginput dan mencetak hasil pemeriksaan darah, lalu menyerahkannya kepada penanggung jawab laboratorium. Penanggung jawab laboratorium menganalisis dan menyimpulkan hasil pemeriksaan darah.

Penanggung jawab laboratorium akan memberikan catatan atau saran khususnya pada parameter darah yang hasilnya di luar nilai normal. Proses ini secara normal membutuhkan waktu 1-2 menit untuk pengambilan spesimen darah dan 2-3 jam untuk mengetahui hasilnya. Gambar 5 memperlihatkan proses bisnis pemeriksaan spesimen darah. 
Proses Bisnis Layanan Medical Checkup (MCU)...

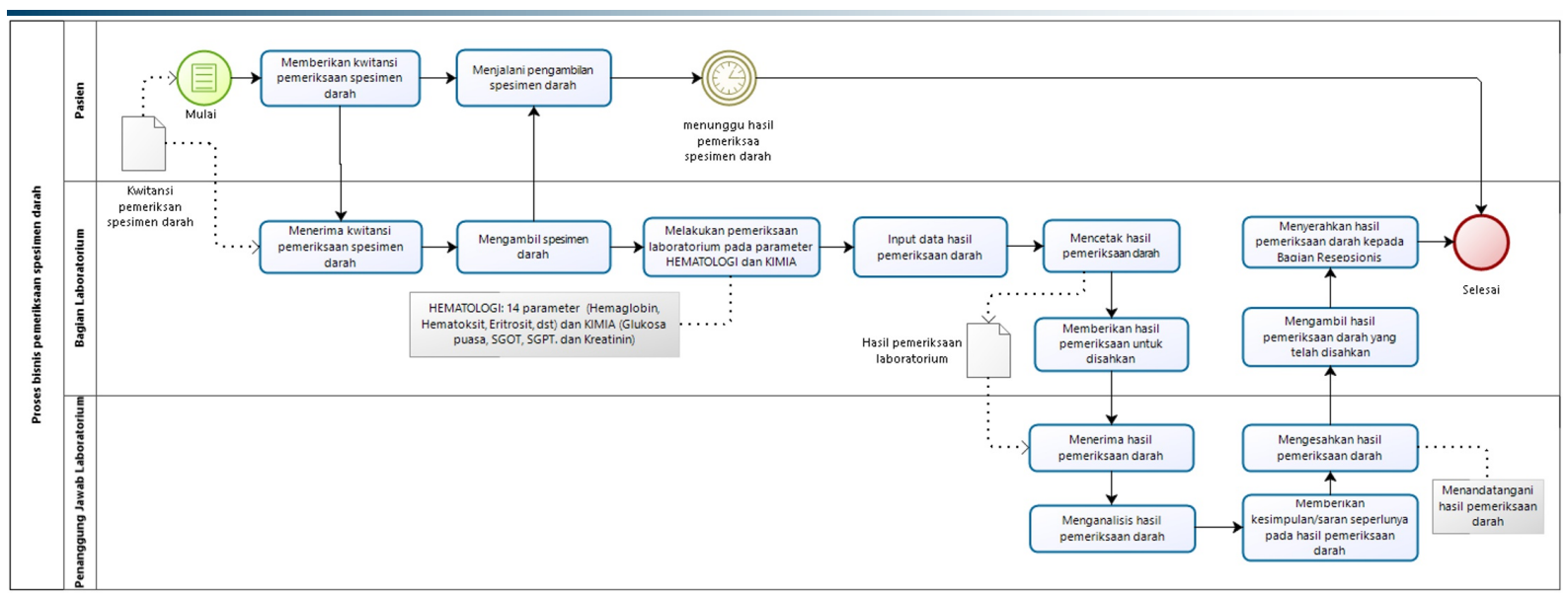

Gambar 5. Proses Bisnis Pemeriksaan Spesimen Darah

\section{Proses Bisnis Pemeriksaan Spesimen} Urine

Setelah menjalani pemeriksaan spesimen darah, pasien menjalani pemeriksaan spesimen urine dengan terlebih dahulu menyerahkan kuitansi pembayaran yang terkait layanan tersebut. Setelah itu, bagian laboratorium memberikan wadah khusus kepada pasien untuk diisi spesimen urine secukupnya.

Bagian laboratorium menggunakan spesimen urine untuk melakukan pemeriksaan terhadap urine rutin mikroskopis urine, kimia urine, dan mikroskopis urine. Pemeriksaan urine rutin mikroskopis urine dilakukan terhadap warna dan kejernihan urine.

Pemeriksaan terhadap kimia urine dilakukan pada sepuluh parameter, yaitu: (1) Berat Jenis; (2) pH; (3) Nitrit; (4) Protein; (5) Glukosa Urine; (6) Keton; (7) Urobilinogen; (8) Bilirubin; (9) Leukosit Esterase; dan (10) Eritrosit. Adapun pemeriksaan mikroskopis urine dilakukan pada enam parameter, yaitu: (1) Eritrosit; (2) Leukosit; (3) Epithel; (4) Bakteri; (5) Kristal; dan (6) Silinder.

Bagian laboratorium menginput dan mencetak hasil pemeriksaan urine dan menyerahkan hasilnya kepada penanggung jawab laboratorium. Penanggung jawab laboratorium menganalisis dan menyimpulkan hasil pemeriksaan urine. Penanggung jawab laboratorium akan memberikan catatan atau saran, khususnya pada parameter urine yang hasilnya di luar batas nilai normal.

Hasil pemeriksaan urine dapat disatukan dengan hasil pemeriksaan darah. Proses ini secara normal membutuhkan waktu 2-3 menit untuk pengambilan spesimen urine dan 3-5 jam untuk mengetahui hasilnya. Gambar 6 memperlihatkan proses bisnis pemeriksaan spesimen urine.

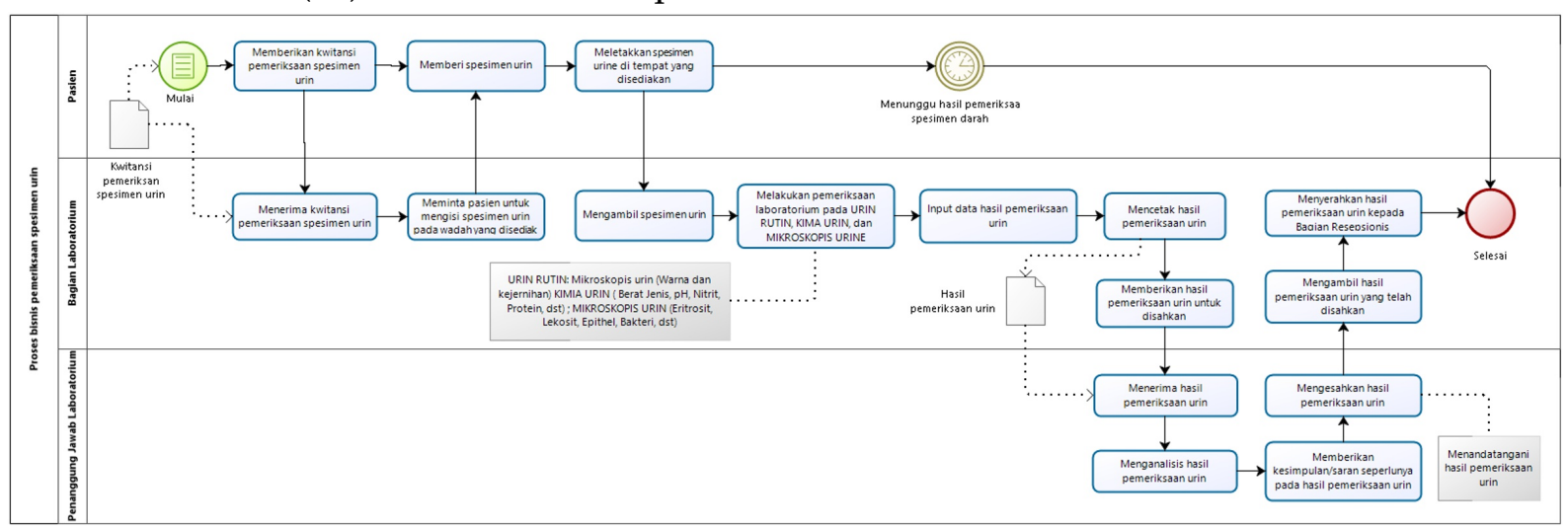

Gambar 6. Proses Bisnis Pemeriksaan Spesimen Urin 


\section{Proses Bisnis Pemeriksaan Thorax}

Setelah menjalani pemeriksaan spesimen urin, pasien menjalani pemeriksaan thorax atau paru-paru dengan terlebih dahulu menyerahkan kuitansi pembayaran terkait layanan tersebut. Bagian radiologi memberitahukan kepada pasien untuk menyesuaikan pakaian dan mengarahkan pasien untuk berdiri pada tempat pengambilan foto thorax. Kemudian, bagian radiologi mengambil foto thorax pasien dan mencetaknya.

Selanjutnya, bagian radiologi memberikan foto thorax pasien kepada dokter radiologi. Dokter radiologi membaca dan menganalisis foto thorax, lalu membuat surat keterangan hasil pemeriksaan thorax. Proses ini secara normal membutuhkan waktu 1-3 detik untuk pengambilan foto thorax dan 2-3 hari untuk mengetahui hasilnya. Gambar 7 memperlihatkan proses bisnis pemeriksaan thorax.

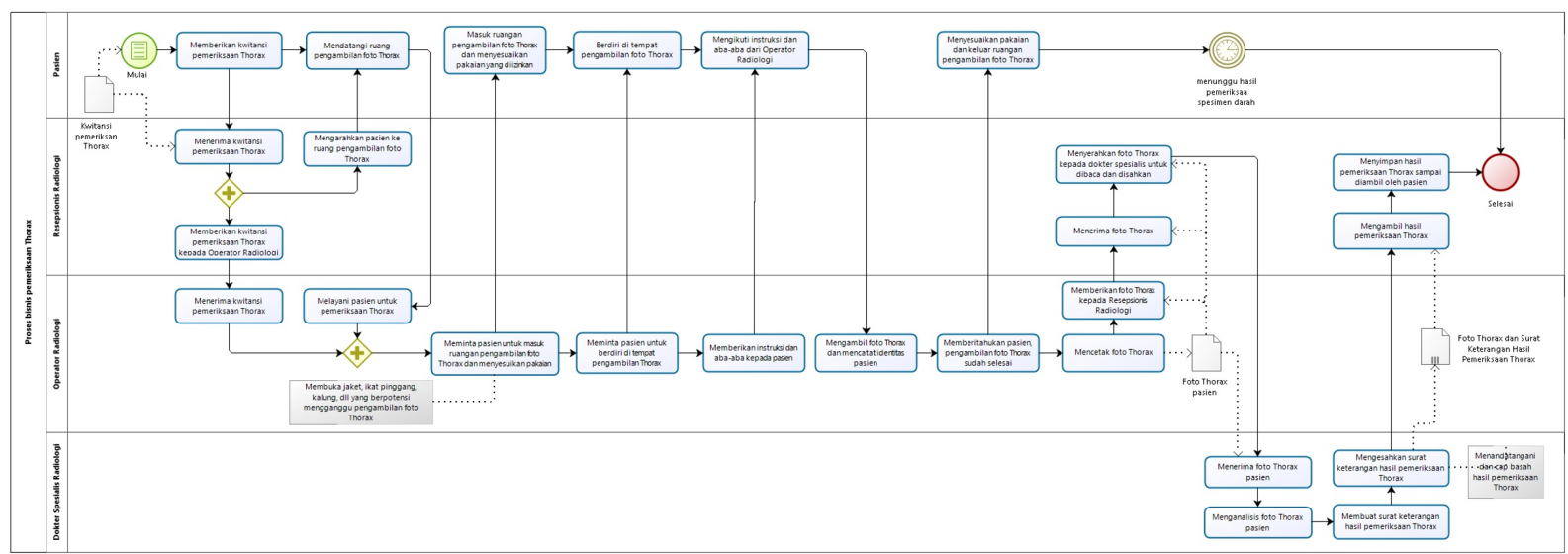

Gambar 7. Proses Bisnis Pemeriksaan Thorax

Proses Bisnis Pengambilan Hasil Pemeriksaan Thorax

Pasien mengambil hasil pemeriksaan thorax dengan terlebih dahulu menunjukkan kuitansi pemeriksaan thorax kepada resepsionis Radiologi. Resepsionis Radiologi mencari hasil pemeriksaan thorax sesuai dengan identitas pasien.

Jika hasil MCU sudah ada, resepsionis Radiologi memberikan hasil pemeriksaan thorax kepada pasien.
Namun, jika hasil pemeriksaan thorax belum ada, resepsionis Radiologi akan mencari hasil pemeriksaan thorax ke dokter spesialis Radiologi atau memberitahukan kepada pasien bahwa hasil pemeriksaan thorax belum selesai dan meminta pasien untuk menunggu sampai hasil pemeriksaan thorax disahkan.

Proses ini secara normal membutuhkan waktu 1-2 menit. Gambar 8

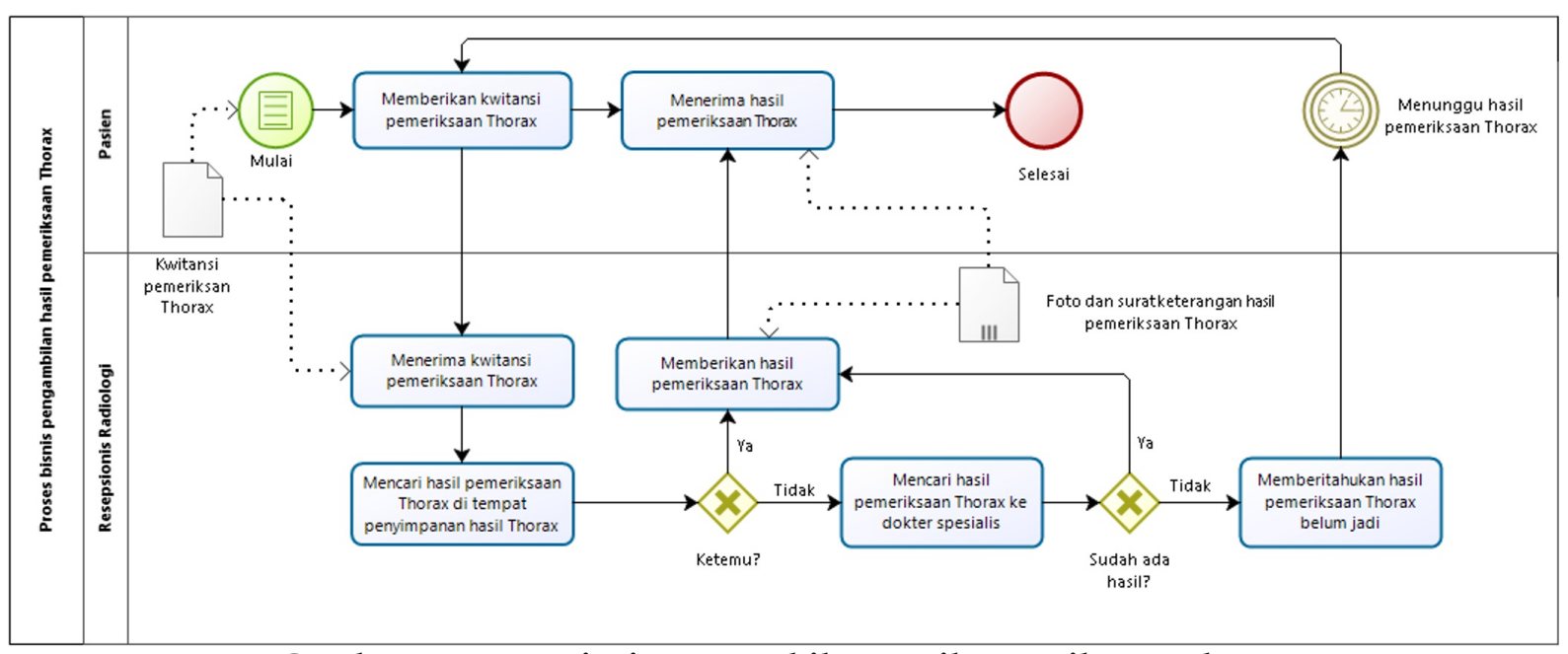

Gambar 8. Proses Bisnis Pengambilan Hasil Pemeriksaan Thorax 
memperlihatkan proses bisnis pengambilan hasil pemeriksaan thorax.

\section{Proses Bisnis Analisis Kesimpulan}

Setelah menjalani pemeriksaan fisik, buta warna, pengambilan spesimen darah dan urin, serta pengambilan hasil pemeriksaan thorax, tahap berikutnya adalah analisis kesimpulan oleh dokter MCU. Pasien menyerahkan surat keterangan hasil pemeriksaan thorax kepada resepsionis MCU, sedangkan foto thorax-nya disimpan sendiri oleh pasien. Resepsionis MCU menyatukan semua hasil pemeriksaan kemudian menyerahkan seluruh berkas kepada dokter MCU.

Dokter memeriksa berkas MCU, lalu memberitahukan hasil MCU kepada pasien. Jika hasil pemeriksaan MCU normal, pasien tidak perlu melakukan pemeriksaan apapun. Sebaliknya, pasien akan diminta untuk berkonsultasi bahkan melakukan tes ulang pada layanan tertentu apabila terdapat indikasi hasil MCU yang tidak memenuhi seluruh syarat pengangkatan PNS atau pasien dinyatakan tidak lulus pemeriksaan MCU. Proses ini secara normal membutuhkan waktu 1-2 menit. Gambar 9 memperlihatkan proses bisnis analisis kesimpulan.

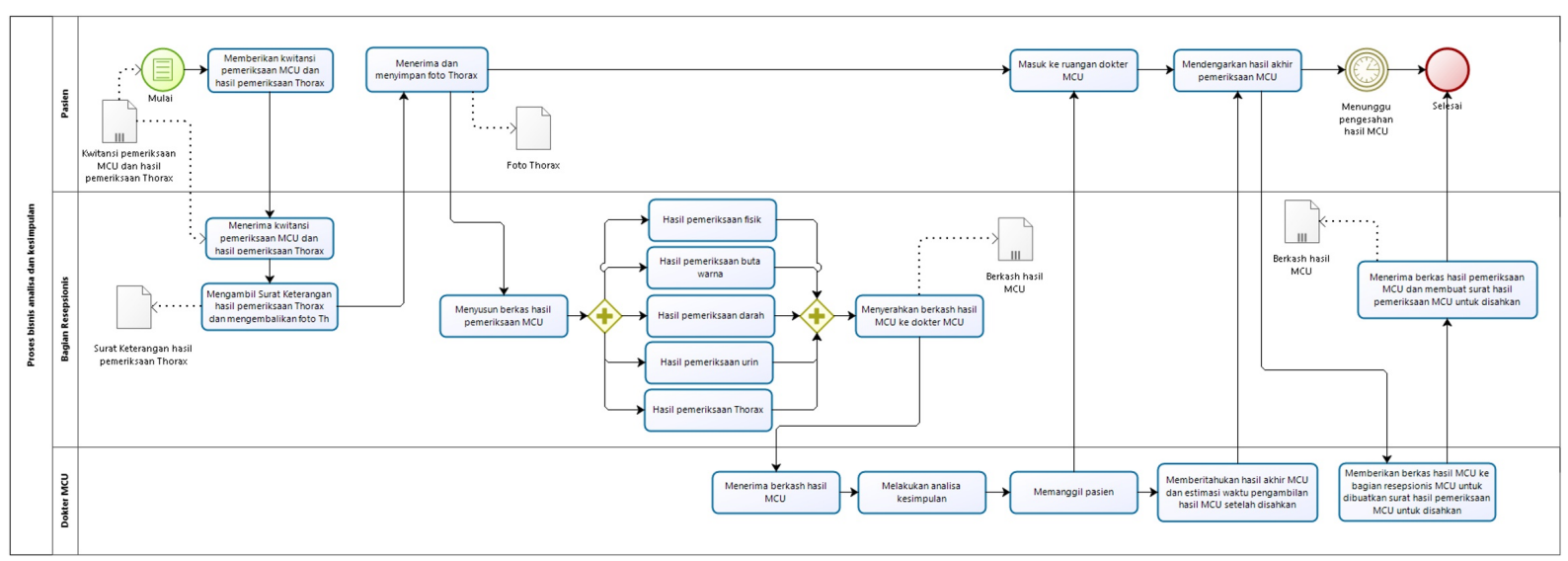

Gambar 9. Proses Bisnis Analisis Kesimpulan

Proses Bisnis Pengesahan Hasil MCU

Pengesahan hasil MCU dilakukan oleh ketua tim penguji kesehatan rumah sakit. Resepsionis MCU membuat surat hasil pengujian MCU. Isi surat diantaranya mencakup nomor surat hasil MCU. Nomor surat tersebut akan dicantumkan sebagai dasar pertimbangan bagi instansi asal pasien dalam mengeluarkan surat keputusan pengangkatan PNS.

Identitas pasien yang dicantumkan di surat hasil MCU adalah nama, NIP, pekerjaan, dan alamat. Selain itu, nomor surat PPK yang dibawa oleh pasien pada saat melakukan pendaftaran MCU, digunakan oleh rumah sakit sebagai dasar dalam mengeluarkan surat hasil pengujian kesehatan pasien.

Hasil MCU mencantumkan nomor PPK dan surat keputusan pengangkatan
PNS mencantumkan nomor hasil MCU. Oleh karena itu, MCU untuk pengangkatan PNS harus membawa surat pengantar dari instansi asalnya. Dengan kata lain, pemeriksaan MCU untuk pengangkatan PNS tidak dapat dilakukan atas inisiatif sendiri. Hal ini dilakukan untuk meminimalisir terjadinya pemalsuan terhadap surat hasil pemeriksaan MCU untuk pengangkatan PNS.

Selain nomor PPK, pada surat hasil MCU juga terdapat empat kemungkinan kondisi kesehatan pasien, yang menentukan pasien tersebut memenuhi syarat pengangkatan PNS atau tidak. Adapun empat kemungkinan tersebut, antara lain: (1) memenuhi syarat semua jenis pekerjaan pada umumnya; memenuhi syarat untuk jenis pekerjaan tertentu; (3) dapat diterima dengan syarat 
untuk (1) dan (2) di atas; (3) untuk sementara belum memenuhi syarat kesehatan dan memerlukan pengobatan/ perawatan dan ujian kesehatan perlu diulang setelah selesai pengobatan/ perawatan atau ditolak untuk sementara; dan (4) tidak memenuhi syarat untuk menjalankan tugas sebagai Pegawai Negeri Sipil atau ditolak.

Salinan hasil pengujian MCU diberikan kepada Kepala Kantor Dinas Kesehatan Provinsi Jawa Barat dan disimpan sebagai arsip rumah sakit. Salinan tersebut harus bisa di-tracing apabila sewaktu-waktu dibutuhkan untuk menguji keabsahan surat hasil MCU. Dengan kata lain, salinan surat tersebut dapat meminimalisir terjadinya pemalsuan terhadap surat hasil MCU untuk pengangkatan PNS.

Resepsionis MCU menyerahkan surat hasil pengujian MCU dengan menyertakan hasil pemeriksaan fisik, laboratorium, dan thorax kepada ketua tim penguji kesehatan untuk disahkan (ditandatangani dan dicap basah). Lama pengesahan biasanya tujuh hari atau tergantung banyaknya pengajuan pengesahan dan kesibukan ketua tim yang berwenang. Bagian administrasi menyimpan surat hasil pengujian MCU yang telah disahkan sampai surat tersebut diambil oleh pasien MCU yang bersangkutan. Gambar 10 memperlihatkan proses bisnis pengesahan hasil MCU.

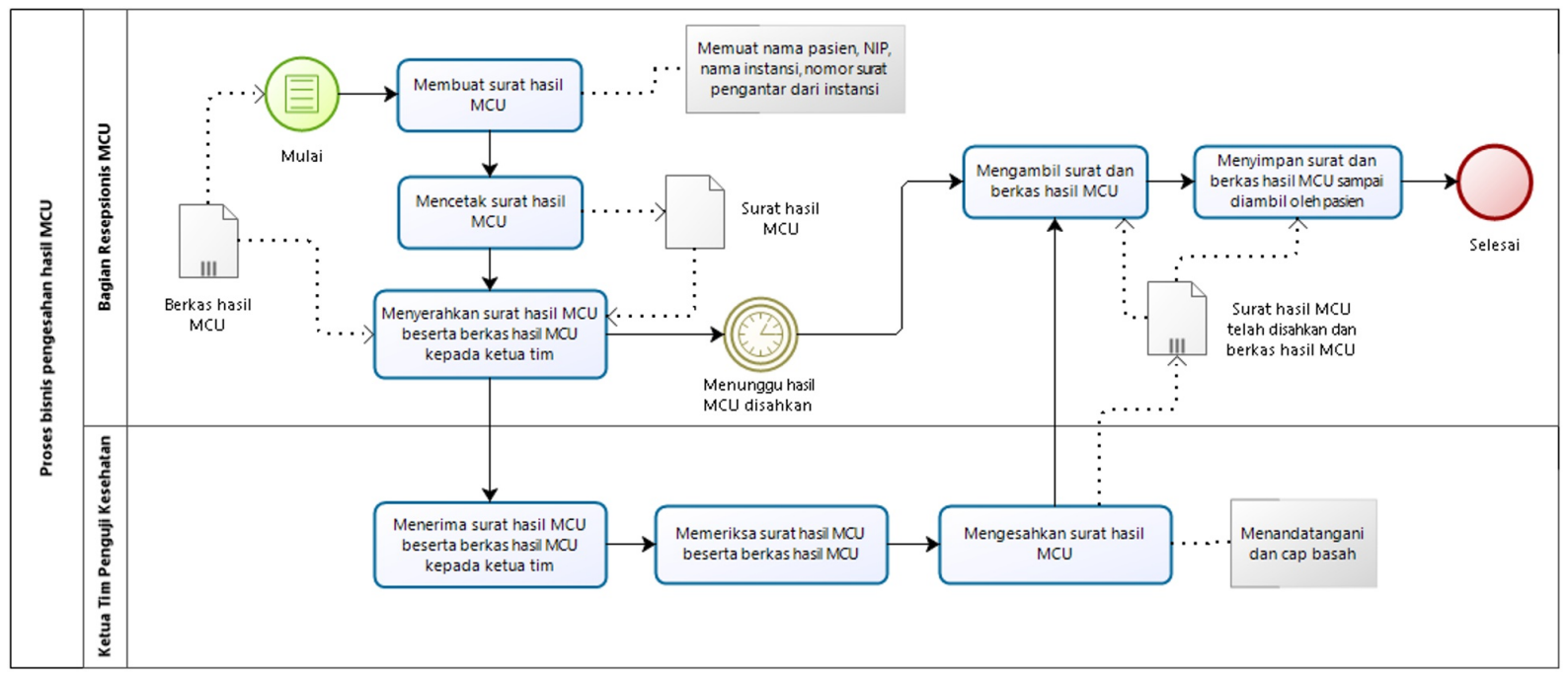

Gambar 10. Proses Bisnis Pengesahan Hasil MCU

Proses Bisnis Pengambilan Hasil MCU

Tahap terakhir dari proses MCU adalah pasien mengambil hasil MCU. Pasien terlebih dahulu menunjukkan kuitansi pemeriksaan MCU atau memberitahukan identitas minimum kepada resepsionis MCU. Resepsionis MCU mencari hasil MCU sesuai dengan identitas pasien. Jika hasil MCU sudah ada, resepsionis MCU memberikan hasil MCU kepada pasien kemudian meminta pasien mengisi berita acara pada buku pengambilan hasil MCU dengan mencantumkan nama, instansi, tanggal pengambilan, dan tanda tangan.
Pasien dapat mengajukan legalisir hasil MCU sebanyak yang dibolehkan oleh resepsionis MCU dengan terlebih dahulu memfotokopi hasil MCU. Namun, jika hasil MCU belum ada, resepsionis MCU akan mencari hasil pemeriksaan MCU ke ketua tim penguji atau memberitahukan kepada pasien bahwa hasil MCU belum selesai dan meminta pasien untuk menunggu sampai hasil MCU disahkan. Proses ini secara normal membutuhkan waktu 1-2 menit. Gambar 11 memperlihatkan proses bisnis pengambilan hasil MCU. 


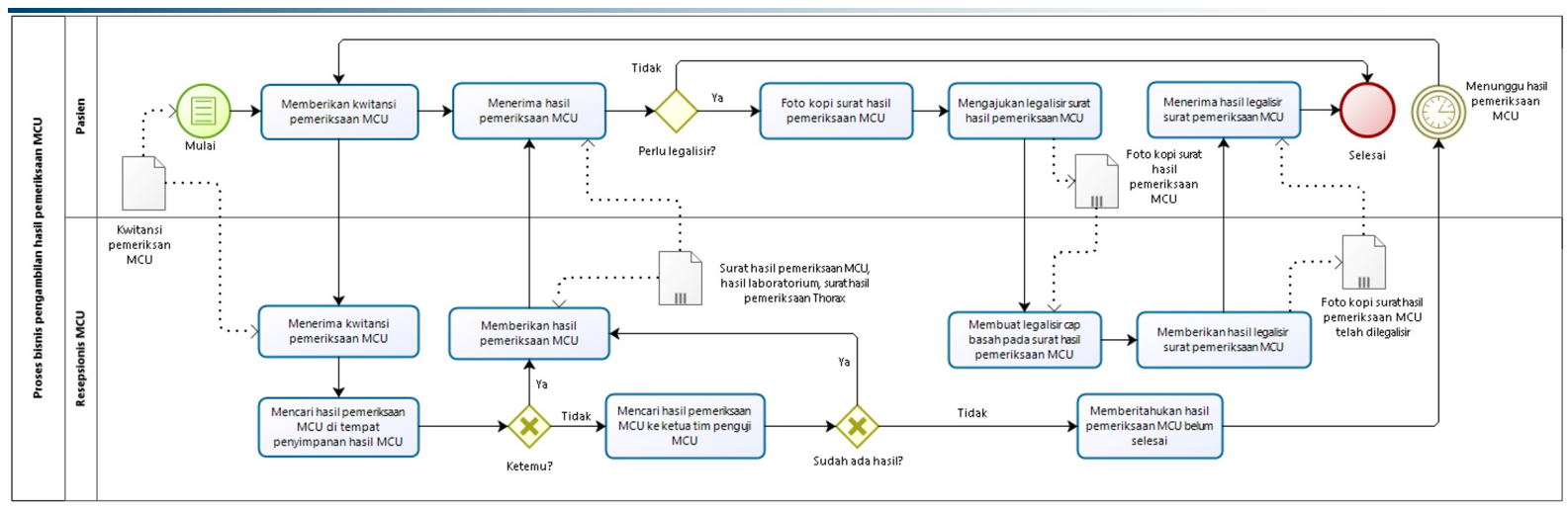

Gambar 11. Proses Bisnis Pengambilan Hasil MCU

PENUTUP

Pemodelan proses bisnis MCU dengan BPMN telah dilakukan menggunakan tool Bizagi. Pemodelan proses bisnis dibuat berdasarkan observasi dan pengalaman penulis menjadi pasien MCU. Selain itu, penulis mempelajari dokumen hasil pemeriksaan MCU seperti dokumen hasil laboratorium, hasil pemeriksaan thorax, dan surat hasil pemeriksaan MCU yang telah disahkan oleh ketua tim penguji kesehatan rumah sakit.

Penelitian ini memberikan pemahaman kepada pasien terhadap proses layanan MCU sehingga pasien lebih siap menjalani MCU baik secara fisik maupun mental. Pasien juga dapat mengetahui setiap proses MCU berada di tahap apa dan memperkirakan kapan proses tersebut akan selesai.

Dari sisi manajemen rumah sakit, proses bisnis ini memudahkan manajemen untuk terus melakukan evaluasi dan meningkatkan layanan $\mathrm{MCU}$ dalam rangka menjaga keunggulan kompetitif yang berkelanjutan. Proses bisnis ini juga dapat diimplementasikan menjadi sebuah SOP MCU di rumah sakit atau klinik yang memiliki layanan MCU. Selain itu, proses bisnis ini merupakan requirement penting untuk membangun perangkat lunak pencatatan data hasil pemeriksaan MCU yang terintegrasi.

Proses bisnis ini masih perlu diuji dan divalidasi oleh stakeholder rumah sakit yang menangani layanan MCU. Pengujian juga perlu melibatkan pasien yang akan menjalani MCU. Selain itu, pengujian untuk mengetahui efektivitas model proses bisnis yang telah dibuat dapat dilakukan dengan simulasi menggunakan tool Business Process Simulation (BPSim). Hal ini memberikan peluang bagi penelitian sejenis di masa mendatang (Hook, 2011; Wynn et al., 2009).

\section{DAFTAR PUSTAKA}

Buttigieg, S., Dey, P. K., \& Gauci, D. (2016). Business process management in health care: current challenges and future prospects. Innovation and Entrepreneurship in Health, 3(1), 1-13. https://doi.org/10.2147/IEH.S68183

Cebeci, C., \& Kol, E. (2013). Analysis for the implementation of the business process management in selected Turkish enterprises. International Journal of Economics and Financial Issues, 3(2), 420-425. http:// www.econjournals.com/index.php/ ijefi/article/view/383

Ciesielska, M., \& Jemielniak, D. (2018). Qualitative Methodologies in Organization Studies Volume II: Methods and Possibilities. In $\mathrm{M}$. Ciesielska \& D. Jemielniak (Eds.), Qualitative methodologies in organization studies (Issue December). Springer International Publishing. https://doi.org/10.1007/978-3-31965442-3

Dechsupa, C., Vatanawood, W., \& Thongtak, A. (2019). Hierarchical Verification for the BPMN Design Model Using State Space Analysis. 
IEEE Access, 7, 16795-16815. https:// doi.org/10.1109/ACCESS.2019.2892958

Fernández, A. D. R., Fernández, D. R., \& García, Y. S. (2020). Business Process Management for optimizing clinical processes: A systematic literature review. Health Informatics Journal, 26(2), 1305-1320. https://doi.org/ 10.1177/1460458219877092

Flowers, R., \& Edeki, C. (2013). Business Process Modeling Notation. International Journal of Computer Science and Mobile Computing, 2(3), 3540. https://www.ijcsmc.com/docs/ papers/March2013/abstracts/ V2I3201305.pdf

Gomes, J., Portela, F., \& Santos, M. F. (2018). Introduction to BPM approach in Healthcare and Case Study of End User Interaction with EHR Interface. Procedia Computer Science, 141, 519524. https://doi.org/10.1016/j.procs. 2018.10.132

Haryanto, A. (2019). Jumlah Kebutuhan PNS Tahun 2019 Capai 254.173 Orang. Tirto.Id. https://tirto.id/jumlahkebutuhan-pns-tahun-2019-capai254173-orang-d9za

Hook, G. (2011). Business Process Modeling and simulation. Proceedings of the 2011 Winter Simulation Conference (WSC), 773-778. https:// doi.org/10.1109/WSC.2011.6147804

Humas RSHS. (2019a). Medical Check Up, Siapa Takut? I Rumah Sakit Dokter Hasan Sadikin Bandung. Web.Rshs.or.Id. http://web.rshs.or.id/ medical-check-up-siapa-takut/

Humas RSHS. (2019b). Medical Check Up I Rumah Sakit Dokter Hasan Sadikin Bandung. Web.Rshs.or.Id. http:// web.rshs.or.id/tarif/medical-check-up/

Idhom, A. M. (2019). Cara Mengecek Jumlah Pendaftar CPNS 2019 Setiap Formasi di SSCN. Tirto.Id. https://tirto.id/caramengecek-jumlah-pendaftar-cpns2019-setiap-formasi-di-sscn-encZ

Juan D, L., S, M., L, M., D, A., Francisco, L., A, V., R, O., M, S., \& D, Y. (2016).
Business Processes Management Implementation in Health Sector. International Journal of Managing Public Sector Information and Communication Technologies, 7(4), 01-10. https:// doi.org/10.5121/ijmpict.2016.7401

Kazemzadeh, Y., Milton, S. K., \& Johnson, L. W. (2015). Process Chain Network (PCN) and Business Process Modeling Notation (BPMN): A Comparison of Concepts. Journal of Management and Strategy, 6(1), 88-99. https://doi.org/10.5430/jms.v6n1p88

Keramati, A., Golian, H. R., \& Mofrad, M. A. (2011). Improving business processes with business process modelling notation and business process execution language: an action research approach. International Journal of Business Information Systems, 7(4), 458-476. https://doi.org/10.1504/ IJBIS.2011.040568

Koncevičs, R., Peņicina, L., Gaidukovs, A., Darğis, M., Burbo, R., \& Auziņš, A. (2017). Comparative Analysis of Business Process Modelling Tools for Compliance Management Support. Applied Computer Systems, 21(1), 2227. https://doi.org/10.1515/acss-20170003

Kufner, J., \& Marik, R. (2019). From a BPMN Black Box to a Smalldb State Machine. IEEE Access, 7(5), 5627656296. https://doi.org/10.1109/ ACCESS.2019.2912567

Lodhi, A., Küppen, V., \& Saake, G. (2011). An Extension of BPMN Meta-model for Evaluation of Business Processes. Scientific Journal of Riga Technical University. Computer Sciences, 43(1), 2734. https://doi.org/10.2478/v10143-0110004-7

Nuzulita, N., Djohan, R. S. A., \& Roiqoh, S. (2020). Supply Chain Management Analysis Using the Business Process Model and Notation in the Midst of Covid-19 Pandemic. Journal of Accounting and Strategic Finance, 3(2), 185-198. https://doi.org/10.33005/ 
jasf.v3i2.144

Ramos-Merino, M., Álvarez-Sabucedo, L. M., Santos-Gago, J. M., \& de ArribaPérez, F. (2019). A Pattern Based Method for Simplifying a BPMN Process Model. Applied Sciences, 9(11), 2322. https://doi.org/10.3390/ app9112322

Recker, J., Rosemann, M., Indulska, M., \& Green, P. (2009). Business Process Modeling- A Comparative Analysis. JAIS Journal of the Association for Information Systems, 10(4), 333-363. https://doi.org/10.17705/1jais.00193

Ruiz, F., Garcia, F., Calahorra, L., Llorente, C., Gonçalves, L., Daniel, C., \& Blobel, B. (2012). Business process modeling in healthcare. Studies in Health Technology and Informatics, 179(May 2014), 75-87. https://doi.org/ 10.3233/978-1-61499-086-4-75

van der Aalst, W. M. P. (2013). Business Process Management: A Comprehensive Survey. ISRN Software Engineering, 2013, 1-37. https://doi.org/10.1155/2013/507984

Wynn, M. T., Verbeek, H. M. W., van der Aalst, W. M. P., ter Hofstede, A. H. M., \& Edmond, D. (2009). Business process verification - finally a reality! Business Process Management Journal, 15(1), 74-92. https://doi.org/ 10.1108/14637150910931479

Yamasathien, S., \& Vatanawood, W. (2014). An approach to construct formal model of business process model from BPMN workflow patterns. 2014 Fourth International Conference on Digital Information and Communication Technology and Its Applications (DICTAP), 211-215. https://doi.org/10.1109/DICTAP. 2014.6821684

Zafar, I., Azam, F., Anwar, M. W., Maqbool, B., Butt, W. H., \& Nazir, A. (2019). A Novel Framework to Automatically Generate Executable Web Services From BPMN Models. IEEE Access, 7, 93653-93677. https:// doi.org/10.1109/ACCESS.2019.2927785 